\title{
PESCA ARTESANAL DO CAMARÃO SETE-BARBAS: UMA CARACTERIZAÇÃO SÓCIO-ECONÔMICA NA PENHA, SC
}

\author{
BAIL. G.C. ${ }^{1} \&$ BRANCO, J.O. ${ }^{2}$ \\ Centro de Ciências Tecnológicas da Terra e do Mar, CTTMar - UNIVALI, \\ Laboratório de Biologia \\ Caixa Postal 360, CEP 88302-202, Itajaí/SC. \\ E-mail: '1gila@univali.br, , ${ }^{2}$ branco@univali.br
}

\begin{abstract}
Bail. G.C. \& Branco, J.O. 2007. Artisanal Fishery of sea-bob-shrimp: a socioeconomic characterization in the Penha, SC. Braz. J. Aquat. Sci. Technol. 11(2):25-32. ISSN 1808-7035. Marine resources exploration along Santa Catarina coast plays an important role in the socioeconomic and cultural context. Considering this information, the elaboration of a management plan for fishery resources should consider beyond the biological, physical and chemical components, the socioeconomic dimension. This work aimed to characterize the socioeconomic profile of the fishermen of sea-bob-shrimp at Penha (Santa Catarina State). To accomplish this characterization, 55 local fishermen were interviewed, regarding scholar instruction of fisherman and their family, data on fishery activity, destination and commercialization of the shrimp and by-catch, and also the gear utilized in the fishery. Results showed an age composition of fishermen predominantly among 40 and 50 years old, confirming that the activity is performed mainly by the elders of the community, which on the other hand, cannot keep their family only with the fishery profits. Such situation is driving the activity to a decline, in a way that fishermen are being obligated to accept informal jobs, putting in risk their survivorship and a rich Azorean culture.
\end{abstract}

Key words: Artisanal fishermen, Socioeconomic aspects, Xiphopenaeus kroyeri

\section{INTRODUÇÃO}

A exploração dos recursos marinhos no litoral de Santa Catarina exerce papel relevante no contexto sócio-econômico e cultural. Essa atividade foi uma dentre os legados da cultura açoriana que contribuiu de maneira expressiva para o desenvolvimento da pesca artesanal e industrial no litoral catarinense (Branco, 1999).

A partir de 1950, com o aumento das embarcações movidas por motor a óleo na frota camaroeira do município de Penha, ocorreu uma verdadeira revolução na pesca regional do camarão sete-barbas (Xiphopenaeus kroyeri), incrementando as capturas da Armação do Itapocoroy em $60 \%$ em relação aos anos anteriores (Souza, 1995).

A pesca tem sido a atividade responsável pelo sustento de grande parte da população mundial (Marchesin \& Rui, 1985 in Oliveira, 1988). No Brasil, a pesca artesanal tem recebido ao longo dos tempos poucos incentivos governamentais. Embora seja uma atividade importante na medida em que abastece local e regionalmente os mercados de pescados, é a atividade principal para uma expressiva parcela da população litorânea (Cabral, 1997).

A situação sócio-econômica do país coloca o pescador artesanal a procura de uma segurança financeira, a qual tem gerado um grande problema social, levando-os a optar por um emprego assalariado ou subemprego. A falta de infra-estrutura e recursos nas localidades pesqueiras faz com que o pescador seja obrigado a comercializar o pescado com "atravessadores"; esses fatores fazem com que o custo final para o consumidor seja elevado, ocasionando a dependência do pescador artesanal com o "atravessador" (Oliveira, 1988). Como em diversas comunidades pesqueiras ao longo da costa do Brasil, a pesca artesanal na região de Penha vem sobrevivendo graças à persistência e resistência desses homens que tiram dela seu sustento e da família.

As pescarias propiciam alimentação e empregos convenientes nas pequenas comunidades, porém os interesses econômicos sobrepõem esses objetivos à mediada que estes se desenvolvem (Hilborn \& Walters, 1992; Lima, 1995; Sachs, 1995 in Betito \& Juliano, 2001).

Atualmente as comunidades pesqueiras vêm sofrendo diversos impactos, colocando em risco suas sobrevivências e a cultura açoriana. A intensa atuação da frota industrial, o crescimento desordenado do turismo e do cultivo de mexilhões vem provocando uma disputa pelo espaço costeiro. A situação dos pescadores artesanais da região sul-sudeste do Brasil é bem mais complexa e crítica. É uma questão de sobrevivência de toda uma classe trabalhadora e de seus familiares, pois as capturas são progressivamente mais escassas em safras cada vez mais curtas que não lhes rendem o sustento anual, forçando-os a aceitarem subempregos nos períodos entre safra (IBAMA, 1993a; Cabral, 1997). 
O manejo de recursos pesqueiros pressupõe um amplo conhecimento do sistema, compreendendo nesse caso a espécie-alvo camarão sete-barbas (X. kroyeri), a fauna acompanhante, $\mathrm{o}$ ambiente e as pessoas envolvidas na atividade de pesca. A forte interação entre esses componentes e suas oscilações no tempo confere complexidade ao sistema, onde as decisões acerca das medidas a serem tomadas serão tão mais apropriadas quanto mais profundas e abrangentes forem às informações dos componentes do sistema que as embasem. Assim, o manejo de recursos pesqueiros, além de seus componentes biológicos, físicos e químicos, tem uma ampla dimensão sócio-econômica que deve ser considerada (Agostinho \& Gomes, 1997). Ressalta-se ainda que os conhecimentos das especificidades sócio-econômicas dos grupos de pescadores são ferramentas importantes para auxiliar em processos que interfiram em sua realidade, principalmente quando nos referimos às políticas públicas $e$ sociais.

A sobrepesca do valioso recurso camaroeiro, que movimenta a economia da região de Penha, indica uma queda gradativa na produção e esgotamento de certos pesqueiros. Tal fato é corroborado por Medeiros et al., (1997), os quais apontam, através de depoimentos informais de pescadores, que há uma diminuição gradativa das capturas de camarões ao longo dos anos, atribuída pelo Grupo Permanente de Estudos de Camarões (IBAMA, 1993b) ao aumento do esforço de pesca empregado. Estudos de D'Incao et al., (2002) sobre avaliação da pesca de camarão sete-barbas na região sudeste e sul do Brasil apresentam uma série histórica de dados que revelam uma tendência de decréscimo ao longo dos anos, contribuindo decisivamente para o declínio da produção geral de sete-barbas. Esses fatos são notados e preocupam toda a comunidade pesqueira que depende da exploração deste recurso para sua sobrevivência. Dessa maneira, este trabalho tem como objetivo caracterizar o perfil sócio-econômico dos atores que compõem o setor produtivo artesanal, visando contribuir para elaboração de programas e/ou políticas que possibilitem uma gestão sustentável dessa importante atividade realizada na região de Penha, SC.

\section{MATERIAL E MÉTODOS}

\author{
Área de Estudo \\ O município de Penha está localizado no litoral \\ centro-norte de Santa Catarina, nas coordenadas $26^{\circ}$ \\ $46^{\prime}$ - $26^{\circ} 48^{\prime} \mathrm{S}$ e $48^{\circ} 39^{\prime}-48^{\circ} 35^{\prime} \mathrm{W}$. Possui uma área \\ de $60,3 \mathrm{~km}^{2}$, limitando-se ao Sul com o município de \\ Navegantes, ao Oeste e Norte com o município de Pi- \\ çarras e a Leste com o oceano Atlântico. A morfologia
}

da região se caracteriza pela formação de diversas baías e enseadas, resultado da intercalação de praias e costões rochosos originados de projeções menores da Serra do Mar em direção ao oceano (Marenzi, 2002).

\section{Trabalho de Campo}

Os dados do presente trabalho foram obtidos mediante a aplicação de entrevistas estruturadas, através de abordagens diretas. As abordagens foram realizadas de forma fragmentada e alheatória ao longo do período de amostragem, diretamente aos pescadores artesanais de camarão sete-barbas. Estes foram entrevistados em seus locais de trabalho e lazer, como praias, ranchos de pesca, trapiches, peixarias, bares e em alguns casos, nas próprias residências dos pescadores.

Na definição da amostra, levaram-se em conta os locais de maior concentração de pescadores artesanais de camarão sete-barbas, de forma a assegurar a representatividade. Tais locais foram previamente identificados e posteriormente visitados, sendo eles: Rio Piçarras, Praia Alegre e Praia do Trapiche, na Armação do Itapocoroy.

O questionário utilizado foi estruturado visando levantar os dados de identificação do pescador, escolaridade do entrevistado e de sua família, atividade pesqueira (horário, local do pesqueiro, tempo, profundidade de arrasto, tipo de petrecho de pesca utilizado), saneamento básico, conservação e destino do camarão e respectiva fauna acompanhante capturada.

Para definição do tamanho da amostra considerou-se o número médio de 76,5 embarcações em atividade na Armação do Itapocoroy (Branco, 1999), o número de visitas a campo, bem como a receptividade dos pescadores abordados, obtendo ao término da aplicação dos questionários um total de 55 entrevistados ao longo de 12 inserções em campo, entre os meses de agosto de 2002 a julho de 2003.

\section{Análise dos Dados}

Os dados obtidos foram tabulados no software Microsoft $₫$ Excel 2002 e apresentados na forma de gráficos e tabelas. Através da análise das informações relativas às temáticas abordadas nos questionários, foi possível apresentar os resultados especificando a freqüência e respectivos percentuais das respostas dadas pelos pescadores.

\section{RESULTADOS}

\section{Caracterização sócio-econômica dos pescadores}

Dos 55 pescadores artesanais entrevistados, a idade variou entre 25 e 68 anos, com $45,5 \%$ na faixa 
etária de 40-50 anos (Fig. 1), sendo que 92,7\% deles são filiados a colônias de pescadores da região (Quadro 1).

Dos entrevistados, $87,3 \%$ eram casados, $9,1 \%$ solteiros e $3,6 \%$ separados. Apenas três pescadores $(5,5 \%)$ não possuíam abastecimento de água fornecido pela CASAN, porém mantinham cachoeira ou poço artesianos em seu terreno e todos eram providos de rede elétrica (Quadro 1).

Em geral, a maior parte das famílias dos entrevistados é composta por quatro pessoas, sendo que $36,4 \%$ dos dependentes são constituídos por duas pessoas e $25,5 \%$ por um dependente (Fig.2). A ausência de dependentes em $9,0 \%$ dos entrevistados, pode ser atribuída aos pescadores na faixa etária de 20 a 30 anos $(9,1 \%)$ (Figs. 1 e 2), que provavelmente não constituíram família,

Em torno de $20,0 \%$ dos pescadores entrevistados informaram ter concluído o ensino fundamental e 1,8\% completaram o médio (Fig. 3 ), entretanto 5,5\% não possuem nenhuma instrução escolar. Em relação às esposas, $54,9 \%$ possuem o fundamental incompleto, $3,9 \%$ médio completo, $2,0 \%$ o ensino superior e 3,9\% não possuem instrução escolar (Fig. 4).

\section{Tempo de atuação na atividade pesqueira}

Cerca de $29,0 \%$ dos pescadores estão na atividade entre 20 e 30 anos, $25,5 \%$ no máximo há 10 anos, $20,0 \%$ de 10 a 20 anos e $1,8 \%$ dos pescadores atuam na atividade pesqueira a cerca de meio século (Fig. 5).

Dos 55 entrevistados, $52,7 \%$ alegam que não conseguem sustentar a família com o rendimento da pesca (Quadro 1), a qual tem rendido de um a cinco salários mínimos por mês; entretanto, $54,5 \%$ ganham no máximo dois salários através das pesca (Fig. 6). Em relação ao número de pessoas da família que estão envolvidas com a pesca, $69,1 \%$ não possuem familiares como ajudantes e $14,5 \%$ tem um membro, $12,8 \%$ dois; $1,8 \%$ três e $1,8 \%$ quatro ou mais familiares na atividade (Quadro 1).

Dos entrevistados, $76,4 \%$ pretendem continuar na profissão (Quadro 1), provavelmente à faixa etária

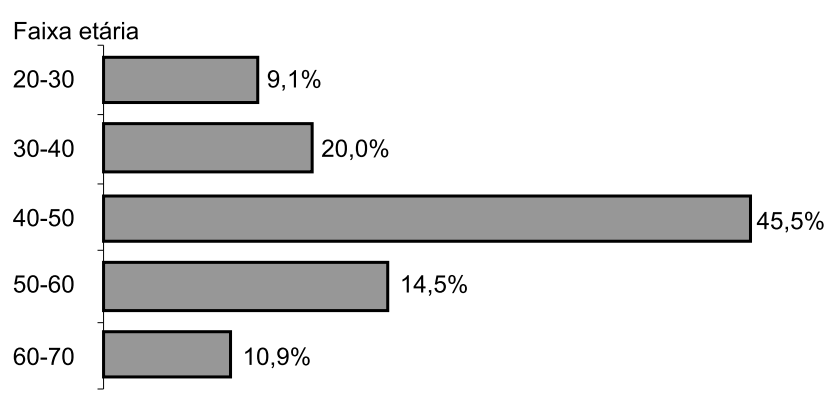

Figura 1 - Distribuição de freqüência relativa da idade dos pescadores artesanais. da maioria dos pescadores (40-50 anos), a qual dificultaria a adaptação em uma nova profissão. Em relação aos filhos, a maioria $(90,9 \%)$ dos pescadores não gostaria que eles seguissem nesta profissão, devido à situação atual da pesca artesanal (Quadro 1). Embora $9,1 \%$ pretendem manter os filhos atuando na pesca, uma vez que estão inseridos por vontade própria (Quadro 1).

A época do defeso para o camarão sete-barbas foi estabelecida com base no ciclo de vida do camarãorosa (Farfantepenaeus paulensis e F. brasiliensis). De acordo com $85,5 \%$ dos entrevistados (Quadro 1), as maiores capturas de camarão sete-barbas ocorrem nos meses do defeso (março, abril e maio), sendo que $96,4 \%$ tem conhecimento correto sobre o período de proibição da atividade pesqueira. Devido as maiores capturas ocorrerem nessa época, $78,2 \%$ dos pescadores afirmam não obedecer ao defeso (Quadro 1), mas se alterada para o período correto, obedeceriam às normas. Quando a fiscalização é intensa no defeso, 47,3\% dos entrevistados não desempenham outra atividade remunerada, enquanto que $16,4 \%$ atuam no cultivo de mexilhões, $36,3 \%$ em atividades ligadas ao comércio (loja, bares), serventes de construção, pintor, fabricação de redes e também na pesca industrial (Quadro 1).

Cerca de $76,4 \%$ dos pescadores não possuem ajudante de pesca, enquanto que dos $23,6 \%$ que possuem, sendo que $84,6 \%$ são parentes; $7,7 \%$ amigos e $7,7 \%$ empregados (Quadro 1). Em relação à manutenção das embarcações, $56,4 \%$ dos entrevistados puxam uma vez ao ano para reparos, $38,2 \%$ duas vezes $\mathrm{e}$ $5,4 \%$ três ou mais vezes (Quadro 1 ).

\section{Dados e equipamentos da Pesca}

O horário de saída para o mar variou entre a 00:00 e 06:00 horas da manhã. O local das pescarias situase entre São Francisco do Sul e Itajaí, 96,4\% dos pescadores alternam as áreas de pesca em função da abundância de camarões, sendo que o tempo médio gasto para chegar ao pesqueiro, dependendo do local onde se encontra a embarcação, variou entre 20 minutos a uma hora e meia. A profundidade de atuação da pesca artesanal variou entre cinco e 25 metros, com tempo médio de arrasto de uma hora e meia.

Os petrechos de pesca utilizados são característicos da frota artesanal que atua na captura do camarão sete-barbas, onde as embarcações mais comuns foram as bateiras, equipadas com tangones, geralmente pequenas ( 7,0 a $8,5 \mathrm{~m}$ de comprimento), desprovidas de casaria e motor de baixa potência (10 a $24 \mathrm{hp}$ ) ou botes-baleeiras, caracterizados por dois tangones, geralmente maiores ( 7,5 a 9,3m), com ou sem casaria e potência de motor maior (10 a 90hp) (Tabela 1). 
Bail \& Branco: Aspectos sócio-econômicos da pesca do camarão.

Quadro 1. Freqüência e respectivos percentuais das respostas obtidas, de acordo com o questionário aplicado. $\mathrm{N}=55$.

\begin{tabular}{|c|c|c|}
\hline COLÔNIA DE PESCADORES & $\mathrm{N}^{\circ}$ & $\%$ \\
\hline $\begin{array}{c}\text { Associados } \\
\text { Não-associados }\end{array}$ & $\begin{array}{l}51 \\
04\end{array}$ & $\begin{array}{c}92,7 \\
7,3\end{array}$ \\
\hline Total & 55 & 100 \\
\hline ESTADO CIVIL & $\mathrm{N}^{\circ}$ & $\%$ \\
\hline $\begin{array}{r}\text { Solteiro } \\
\text { Casado } \\
\text { separado }\end{array}$ & $\begin{array}{l}05 \\
48 \\
02\end{array}$ & $\begin{array}{c}9,1 \\
87,3 \\
3,6\end{array}$ \\
\hline Total & 55 & 100 \\
\hline SANEAMENTO BÁSICO & $\mathrm{N}^{\circ}$ & $\%$ \\
\hline $\begin{array}{l}\text { Fornecimento Casan } \\
\text { Cachoeira } \\
\text { Poço simples }\end{array}$ & $\begin{array}{l}52 \\
02 \\
01\end{array}$ & $\begin{array}{c}94,5 \\
3,6 \\
1,9\end{array}$ \\
\hline Total & 55 & 100 \\
\hline CONSEGUE SUSTENTAR A FAMÍLIA COM A RENDA DA PESCA & $\mathrm{N}^{\circ}$ & $\%$ \\
\hline $\begin{array}{c}\text { Sim } \\
\text { Não }\end{array}$ & $\begin{array}{l}26 \\
29\end{array}$ & $\begin{array}{l}47,3 \\
52,7\end{array}$ \\
\hline Total & 55 & 100 \\
\hline No FAMILIARES ENVOLVIDOS NA PESCA & $\mathrm{N}^{\circ}$ & $\%$ \\
\hline $\begin{array}{c}1 \\
2 \\
3 \\
4 \text { ou mais } \\
\text { nenhum }\end{array}$ & $\begin{array}{l}08 \\
07 \\
01 \\
01 \\
38\end{array}$ & $\begin{array}{c}14,5 \\
12,8 \\
1,8 \\
1,8 \\
69,1\end{array}$ \\
\hline Total & 55 & 100 \\
\hline Pretende continuar na pesca & $\mathrm{N}^{\circ}$ & $\%$ \\
\hline $\begin{array}{l}\text { Sim } \\
\text { Não }\end{array}$ & $\begin{array}{l}42 \\
13\end{array}$ & $\begin{array}{l}76,4 \\
23,6\end{array}$ \\
\hline Total & 55 & 100 \\
\hline Pretende manter os filhos na pesca & $\mathrm{N}^{\circ}$ & $\%$ \\
\hline $\begin{array}{l}\text { Sim } \\
\text { Não }\end{array}$ & $\begin{array}{l}05 \\
50\end{array}$ & $\begin{array}{r}9,1 \\
90,9\end{array}$ \\
\hline Total & 55 & 100 \\
\hline Meses de melhores capturas & $\mathrm{N}^{\circ}$ & $\%$ \\
\hline $\begin{array}{l}\text { Defeso } \\
\text { Outros meses }\end{array}$ & $\begin{array}{l}47 \\
08\end{array}$ & $\begin{array}{l}85,5 \\
14,5\end{array}$ \\
\hline Total & 55 & 100 \\
\hline Sabem quais os meses de defeso & $\mathrm{N}^{\circ}$ & $\%$ \\
\hline $\begin{array}{c}\text { Sabe } \\
\text { Não sabe }\end{array}$ & $\begin{array}{l}53 \\
02\end{array}$ & $\begin{array}{c}96,4 \\
3,6\end{array}$ \\
\hline Total & 55 & 100 \\
\hline Obedece a época de defeso & $\mathrm{N}^{\circ}$ & $\%$ \\
\hline $\begin{array}{l}\text { Sim } \\
\text { Não }\end{array}$ & $\begin{array}{l}12 \\
43\end{array}$ & $\begin{array}{l}21,8 \\
78,2\end{array}$ \\
\hline Total & 55 & 100 \\
\hline \multicolumn{3}{|l|}{ Desempenha outra atividade durante o defeso } \\
\hline $\begin{array}{c}\text { Não } \\
\text { Maricultura } \\
\text { Outras }\end{array}$ & $\begin{array}{c}26 \\
9 \\
20\end{array}$ & $\begin{array}{l}47,3 \\
16,4 \\
36,3\end{array}$ \\
\hline Total & $\mathbf{N}^{\circ}$ & $\%$ \\
\hline \multicolumn{3}{|l|}{ Possui ajudante de pesca } \\
\hline $\begin{array}{l}\text { Sim } \\
\text { Não }\end{array}$ & $\begin{array}{l}13 \\
42\end{array}$ & $\begin{array}{l}23,6 \\
76,4\end{array}$ \\
\hline Total & 55 & 100 \\
\hline Quem são os ajudantes & $\mathrm{N}^{\circ}$ & $\%$ \\
\hline $\begin{array}{l}\text { Parente } \\
\text { Amigo } \\
\text { Amnregado }\end{array}$ & $\begin{array}{c}11 \\
1 \\
1\end{array}$ & $\begin{array}{c}84,6 \\
7,7 \\
7,7\end{array}$ \\
\hline Empregado & 1 & 7,7 \\
\hline Total & 13 & 100 \\
\hline Manutenção da embarcação & $\mathbf{N}^{\circ}$ & $\%$ \\
\hline $1 \times$ ao ano & 31 & 56,4 \\
\hline $2 \times$ ao ano & 21 & 38,2 \\
\hline $3 \times$ ou mais ao ano & 03 & 5,4 \\
\hline Total & 55 & 100 \\
\hline Muda o local de pesca & $\mathrm{N}^{\circ}$ & $\%$ \\
\hline $\begin{array}{l}\text { Sim } \\
\text { Não }\end{array}$ & $\begin{array}{l}53 \\
02\end{array}$ & $\begin{array}{c}96,4 \\
3,6\end{array}$ \\
\hline Total & 55 & 100 \\
\hline
\end{tabular}




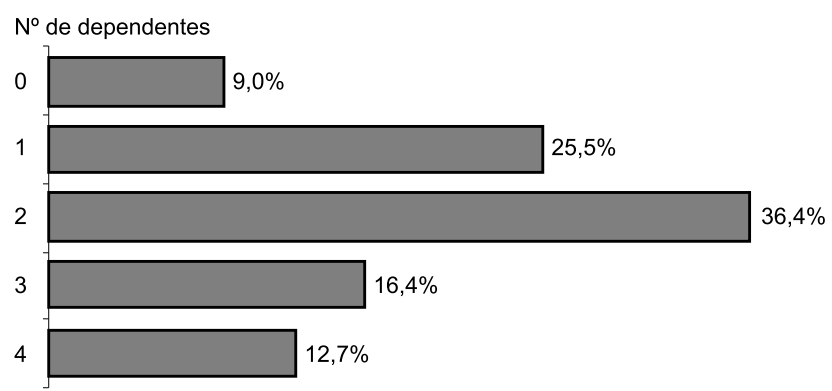

Figura 2 - Freqüência do número de filhos de cada pescador entrevistado.

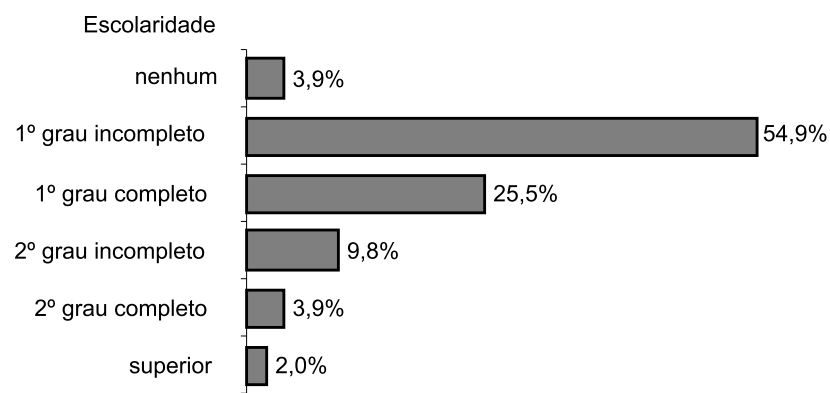

Figura 4 - Distribuição da freqüência de escolaridade das esposas dos pescadores entrevistados.

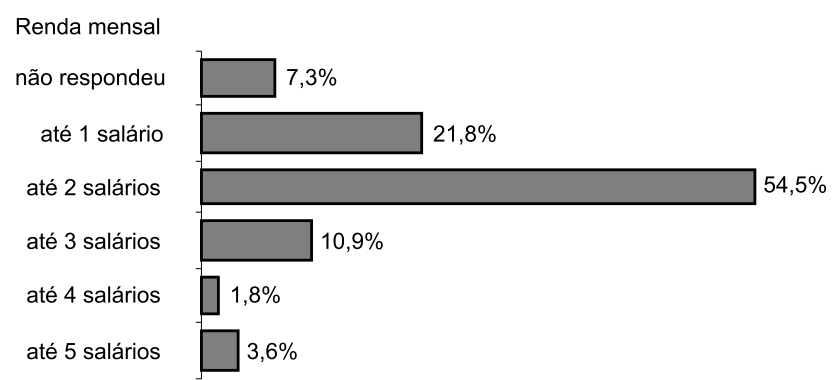

Figura 6 - Renda mensal bruta obtida através da pesca artesanal do camarão sete-barbas.

Dos 55 pescadores entrevistados, $87,3 \%$ possuíam embarcações próprias, 7,3\% em sociedade e 5,4\% emprestadas (Quadro 2).

O tamanho das redes utilizadas na captura do camarão sete-barbas variou de 6,8 a $13,6 \mathrm{~m}$, sendo que $49,1 \%$ dos pescadores adotam redes de $10,20 \mathrm{~m}$. Em relação ao tamanho de malha, esta variou de 10 a $40 \mathrm{~mm}$, sendo que $23,6 \%$ utilizavam a de $20 \mathrm{~mm}$ (Quadro 2).

\section{Destino da captura - camarão}

Os camarões capturados pela pesca artesanal até serem desembarcados, em torno de quatro a seis horas, são mantidos em cestos por $49,1 \%$ dos pescadores, no gelo por $41,8 \%$, e $1,8 \%$ em metasulfito de

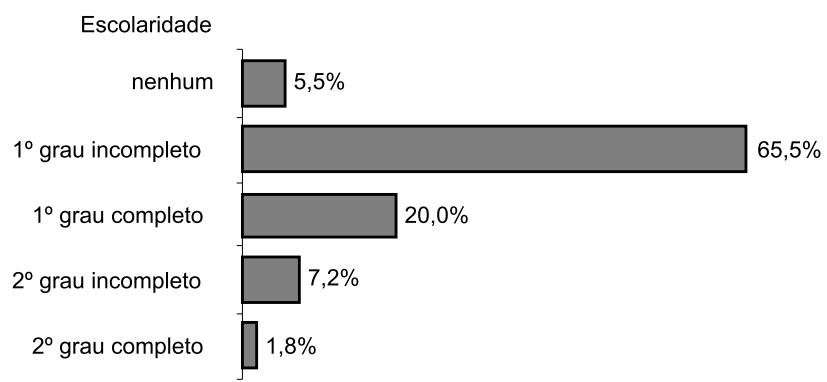

Figura 3 - Distribuição da freqüência de escolaridade dos pescadores entrevistados.

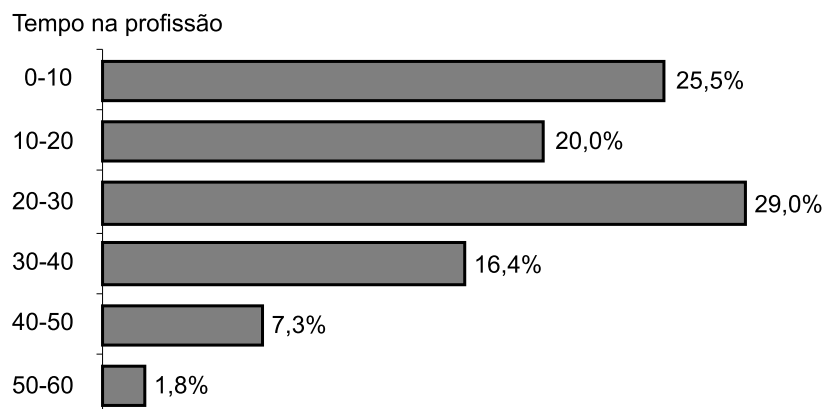

Figura 5 - Tempo na atividade de pescador, de acordo com o questionário aplicado.

Tabela 1 - Características dos barcos utilizados na pesca artesanal do camarão sete-barbas, em Penha, SC.

\begin{tabular}{ccccc}
\hline \hline Tipo de barco & tamanho & casaria & motor & potência \\
\hline lancha/bateira & 7,0 a $8,5 \mathrm{~m}$ & sem & yanmar & 10 a $24 \mathrm{hp}$ \\
bote/baleeira & 7,5 a $9,3 \mathrm{~m}$ & com/sem & yanmar/agrale/tobata & 10 a $90 \mathrm{hp}$ \\
\hline \hline
\end{tabular}

potássio. Os 7,3\% restantes conservam o camarão de acordo com a estação do ano (Quadro 2).

A venda dos camarões varia, conforme a abundância e concorrência no mercado. Dependendo da época e ano (2002 foi considerado ano de safra) o preço do quilo do camarão sete-barbas sujo (com casca) variou de $R \$ 1,30$ a 4,00, com valor médio de 2,00 reais. Do camarão branco alcançou de $R \$ 7,00$ a 20,00, vendido a 12,00 reais em média. Já para o camarão rosa, o preço do quilo atingiu os maiores valores, variando de $\mathrm{R} \$ 20,00$ a 30,00 (média de 22,00 reais). Esses camarões com casca são geralmente comercializados na praia (quando a embarcação chega do mar), diretamente nas casas dos pescadores ou oferecidos a particulares, e ainda para as peixarias da região. $58,2 \%$ dos pescadores possuem freezer, o que pode facilitar na estocagem e venda posterior (Quadro 2).

Os camarões descascados (limpos) alcançam preços mais elevados, onde o quilo do sete-barbas variou de $R \$ 4,50$ a 12,00, com média de 7,00 reais. Já $63,6 \%$ dos entrevistados não costumam descascar o 
Bail \& Branco: Aspectos sócio-econômicos da pesca do camarão.

Quadro 2 - Freqüência e respectivos percentuais das respostas obtidas sobre o destino do camarão, fauna acompanhante e petrechos de pesca utilizados, de acordo com o questionário aplicado. $\mathrm{N}=55$.

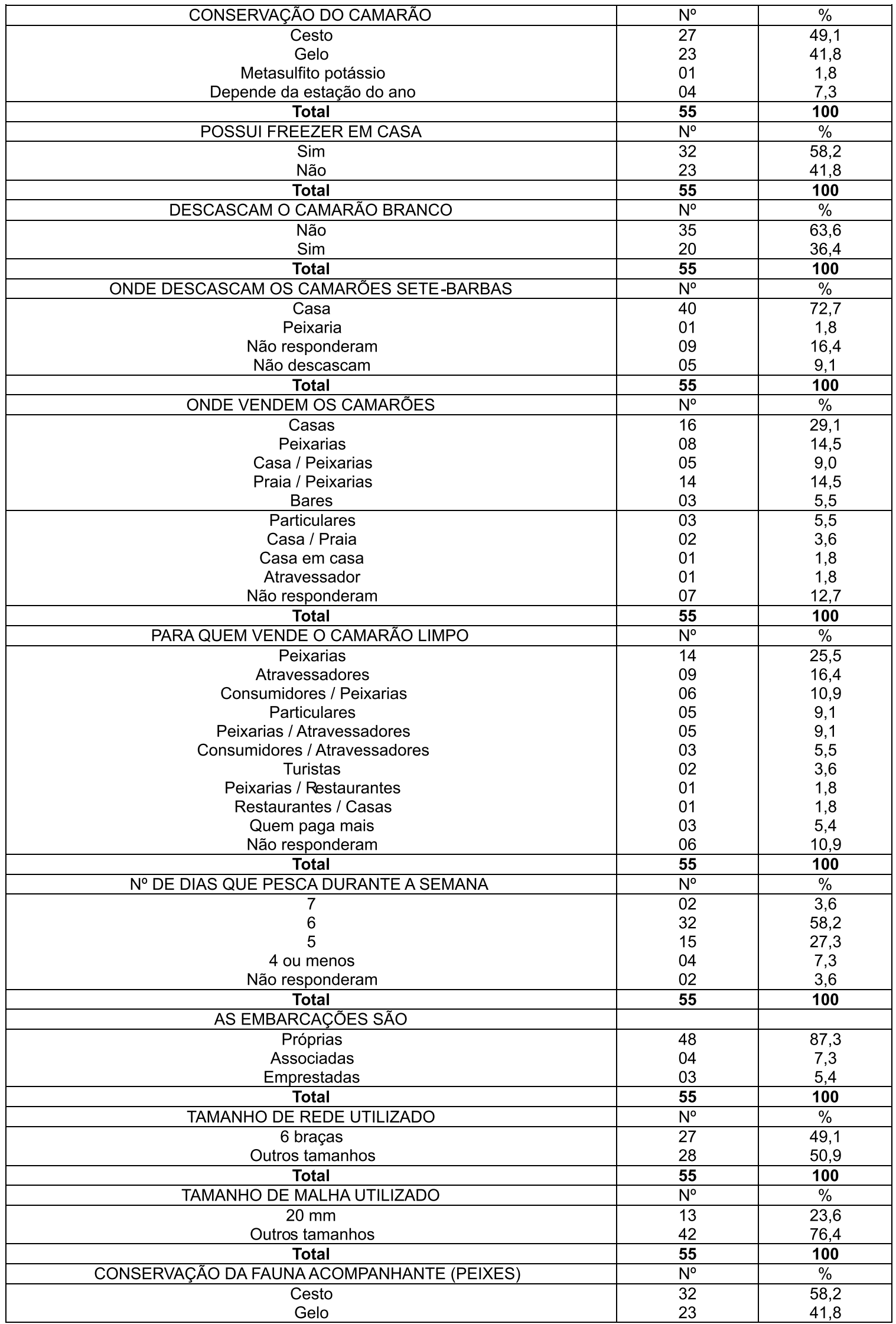


camarão-branco, mas os que o fazem, vendem entre $\mathrm{R} \$ 8,00$ e $25,00 \mathrm{~kg}$, sendo a média de preço de 20,00 reais. Para o camarão-rosa, pode variar de $\mathrm{R} \$ 20,00$ a 50,00 , porém geralmente esta espécie não ocorre na região de Penha.

Dos pescadores que descascam os camarões, $72,7 \%$ limpam em casa, $1,8 \%$ na peixaria e $16,4 \%$ não responderam esta pergunta. Com relação à venda, $29,1 \%$ comercializam em casa, $14,5 \%$ em peixarias, $9,0 \%$ em casa-peixaria, $14,5 \%$ na praia-peixarias, $5,5 \%$ em bares, $5,5 \%$ para particulares, 3,6 em casa-praia, $1,8 \%$ de casa em casa, $1,8 \%$ para atravessador e $12,7 \%$ não responderam à pergunta (Quadro 2 ).

O camarão limpo é vendido por $25,5 \%$ dos pescadores para peixarias da região, 16,4\% para atravessadores, 10,9\% para consumidor e peixaria, $9,1 \%$ particulares, $9,1 \%$ em peixaria e atravessadores, $5,5 \%$ para consumidor e atravessador, $3,6 \%$ para turistas, $1,8 \%$ em peixarias e restaurantes, $1,8 \%$ em restaurantes e casas e os $5,4 \%$ vendem para quem pagar mais (Quadro 2).

Dos 55 entrevistados, $58,2 \%$ pescam seis dias por semana, $27,3 \%$ cinco dias, $7,3 \%$ quatro ou menos dias por semana, 3,6\% pescam sete dias por semana, e 3,6\% não responderam a essa pergunta (Quadro 2), totalizando em média oito meses de pesca por ano. De acordo os pescadores artesanais, as maiores capturas registradas na Armação do Itapocoroy de camarão sete-barbas atingiram até $700 \mathrm{~kg}$ em um dia de pesca.

\section{- fauna acompanhante}

A fauna acompanhante capturada na pesca do camarão sete-barbas é constituída principalmente por peixes, onde parte destes são considerados aproveitáveis. Segundo os entrevistados, $58,2 \%$ conservam os peixes em cestos e $41,8 \%$ em gelo (Quadro 2).

As espécies mais capturadas foram a maria-luiza (Paralonchurus brasiliensis), cangoá (Stellifer spp.), tortinha (Isopisthus parvipinnis), pescadas e robalos. Em relação ao descarte, devido as maiores abundâncias e o pequeno porte das maria-luiza e cangoá, estas são comumente descartadas. Alguns pescadores afirmam que rejeitam todas as espécies, enquanto outros chegam a descartar até os camarões miúdos, devido ao difícil processamento em terra.

Os peixes considerados aproveitáveis para consumo humano são vendidos por $30,9 \%$ dos pescadores, já $69,1 \%$ consomem ou doam para pessoas menos favorecidas. O preço por quilo de peixes variou entre $R \$ 0,20$ a 2,50 . Dos $94,55 \%$ pescadores que consomem os peixes aproveitáveis, geralmente utilizam as maria-luiza, pescadas e corvinas.

\section{DISCUSSÃO}

Atualmente as comunidades pesqueiras vêm sofrendo diversos impactos, colocando em risco suas sobrevivências e a cultura açoriana. A intensa atuação da frota industrial, o crescimento desordenado do turismo e do cultivo de mexilhões vem causando problemas às comunidades pesqueiras artesanais, provocando uma disputa constante pelo espaço costeiro.

De acordo com Medeiros et al. (1997), diversas famílias de pescadores encontram-se espalhadas pelo litoral Centro-Norte de Santa Catarina, concentrandose, muitas vezes, em baías e enseadas, o que proporciona facilidades para a atividade pesqueira.

De acordo com o presente estudo, a composição etária dos pescadores que atuam na região de Penha predominou entre 40 e 50 anos, o que é corroborado por Medeiros et al. (1997), onde a pesca artesanal é exercida, principalmente pelos pescadores mais velhos da comunidade; estes autores acreditam que os pescadores mais novos estejam envolvidos na pesca industrial, a qual é mais rentável.

Estudos de Oliveira (1988) sobre os problemas sócio-econômicos dos pescadores artesanais de Guaiúba, Imbituba (SC), revelam que $82,0 \%$ dos pescadores possuem instruções primárias. Apesar de a maioria possuir certo grau de escolaridade, Medeiros et al. (1997) acreditam que na prática, grande parte dos pescadores é analfabeta devido ao tempo que os mesmos estão sem estudar. É consenso entre os pescadores que níveis de instruções mais elevados são necessários para a obtenção de trabalhos rentáveis, porém, cerca de $76,36 \%$ dos entrevistados neste estudo, pretendem continuar na profissão. Comportamento semelhante foi observado por Agostinho \& Gomes (1997), no Reservatório de Segredo, PR; provavelmente porque cerca de $47,0 \%$ dos pescadores entrevistados vivem exclusivamente da pesca, conseguindo retirar desta, o sustento familiar. Medeiros et al. (1997) demonstram que a maior parte dos pescadores artesanais vive exclusivamente da pesca, mantendo empregos alternativos somente em épocas de entressafras. No presente estudo, $52,74 \%$ dos entrevistados afirmam não conseguir sustentar a família somente através da pesca, o que é corroborado por Oliveira (1988).

Em torno de $50,0 \%$ dos pescadores informaram que durante o defeso, quando a fiscalização é intensa, ficam sem desenvolver outra atividade econômica, os demais procuram fontes alternativas de renda como cultivo de mexilhões, serviços gerais no comércio, embarques na pesca industrial e outras atividades que não exigem escolaridade. 
A pesca artesanal vem sofrendo impactos ao longo de sua existência, onde a falta de fiscalização correta, a ausência de uma política de apoio à pesca, a falta de cooperativas e a diminuição gradativa das capturas ao longo dos anos levam a um declínio dos pescadores artesanais atuantes, os quais acreditam no descaso das autoridades competentes para com o setor artesanal (Medeiros et al., 1997). Desta forma, a falta de conhecimento da realidade das comunidades dificulta consideravelmente qualquer programa de manejo da pesca artesanal.

\section{REFERÊNCIAS}

Agostinho, A. A. \& Gomes, L. C. 1997. Reservatório de Segredo: bases ecológicas para o manejo. Ed. Universidade Estadual de Maringá. 387 p.

Betito, R. \& Juliano, P. A. P. 2001. Educação Ambiental - Perspectivas de solução para a pesca artesanal e industrial em Rio Grande (RS - Brasil): A interação de fatores políticos, sociais, econômicos e ecológicos. Vol. Especial Abril/Maio/Junho. Versão eletrônica dos Anais do III Seminário sobre representações e modelagem no processo de ensino-aprendizagem. Rev. eletrônica Mestr. Educ. Ambient., p. 405-433.

Branco, J. O. 1999. Biologia do Xiphopenaeus kroyeri (Heller, 1862) (Decapoda: Penaeidae), análise da fauna acompanhante e das aves marinhas relacionadas a sua pesca, na região de Penha, SC, Brasil. Tese de Doutorado. Universidade de São Carlos, SP. $147 \mathrm{p}$.
Cabral, C. A. R. 1997. A educação ambiental ma pesca artesanal do camarão-rosa (Penaeus paulensis) em Rio Grande: Análise de uma tentativa. Dissertação de mestrado em Educação Ambiental, FURG. 237 p.

D'Incao, F.; Valentini, H. \& Rodrigues, L. F. 2002. Avaliação da pesca de camarões nas regiões Sudeste e Sul do Brasil. 1965-1999. Atlântica, 24(2): 103116.

IBAMA. 1993a. Relatório das reuniões dos Grupos Permanentes de Estudos, Peixes demersais. Série Estudos de Pesca, 8: 93 p.

IBAMA. 1993b. Camarões do sudeste e sul. Coleção Meio Ambiente: Série Estudos de Pesca, 5: $68 \mathrm{p}$.

Marenzi, A. W. C. 2002. A influência do Cultivo de Mexilhões sobre o habitat bentônico na enseada da Armação do Itapocoroy, Penha, SC. Tese de Doutorado. Universidade Federal de São Carlos, SP. $120 \mathrm{p}$.

Medeiros, R. P.; Polette, M.; Vizinho, S. C.; Macedo, C. X. \& J. C. Borges. 1997. Diagnóstico sócio-econômico e cultural nas comunidades pesqueiras artesanais do litoral Centro-Norte do estado de Santa Catarina. Notas Téc. FACIMAR. 1:33-42.

Oliveira, Z. O. P. 1988. Pesca artesanal: Problemas sociais e econômicos dos pescadores de Guaiúba. Imbituba (SC). Monografia apresentada no curso de Geografia. Fundação de Ensino Pólo Geoeducacional do Vale do Itajaí. $48 \mathrm{p}$.

Souza, C. B. \& Filho, G. A. S. 1995. Penha: a história para todos. Ed. Paralelo 27, Florianópolis, $135 \mathrm{p}$. 